\title{
Rh system and intrauterine growth. Interaction with season of birth
}

\author{
F. Gloria-Bottini ${ }^{\mathrm{a}}$, G.F. Meloni ${ }^{\mathrm{b}}$, A. Finocchi ${ }^{\mathrm{a}}$, \\ S. Porcu ${ }^{\mathrm{b}}$, A. Amante ${ }^{\mathrm{a}}$ and E. Bottini ${ }^{\mathrm{a}, *}$ \\ ${ }^{\mathrm{a}}$ Chair of Preventive and Social Pediatrics, University \\ of Rome Tor Vergata, School of Medicine, Rome, Italy \\ ${ }^{\mathrm{b}}$ Department of Pediatrics, University of Sassari, \\ School of Medicine, Sassari, Italy
}

Received 3 January 2000

Accepted 28 June 2000

Based on the hypothesis that maternal-fetal genetic differences in membrane transport and signal transduction may influence intrauterine development, the recent acquisition on transport function of $\mathrm{Rh}$ protein prompted us to study the relationship between joint maternal-fetal Rh phenotype and birth weight. Considering that metabolic effect of maternalfetal competition could be amplified by environmental conditions, we have investigated possible seasonal effects on such relationship.

We have studied 5291 infants born in Sardinia in the period January 1993-December 1996 and 984 infants born in Rome during 1996.

In $\mathrm{Rh}(-)$ mothers there is a significant association between season of birth and birth weight that shows the highest mean value in infants born in autumn (i.e. conceived in winter). The association is much more evident in male than in female infants. In male infants from $\mathrm{Rh}(-)$ mothers, the association between birth weight and season is significant in $\mathrm{Rh}(+)$ male newborns only.

Recent observations by our group in NIDDM suggest that glucose transport in RBC may be related to D protein, thus we propose an interpretation of the present observation in terms of transport function. When the density of $\mathrm{D}$ protein in the infant is greater than in the mother, the balance is in favour of the infant who may attain a significant developmental advantage when conceived in the cold season.

Keywords: Rhesus system, intra-uterine growth, seasonality

${ }^{*}$ Correspondence to: Prof. Egidio Bottini, Dipartimento di Biopatologia e Diagnostica per Immagini, Facoltà di Medicina, Via della ricerca scientifica, snc, 00133 Roma, Italy. Tel.: +39 6 72596030; Fax: +396 72596028; E-mail: bottini@med.uniroma2.it.

\section{Introduction}

Recent studies have shown that $\mathrm{Rh}$ locus is composed of two genes: $\mathrm{RhD}$, which encodes the major $\mathrm{D}$ antigen and is present only in Rh-positive genomes, and $\mathrm{RhCE}$, which encodes both $\mathrm{Cc}$ and Ee polipeptides, most likely by alternative splicing events. Several membrane components including the $\mathrm{Rh}$ proteins and other glycoproteins recently characterized are probably different subunits of an oligomeric complex with transport function in the erythrocyte $[3,9,13]$. Rh may play an important role in the organization of membrane phospholipids and/or membrane expression of various glycoproteins [1]. Variations of lipid bilayer, on the other hand, could influence the function of various proteins involved in substrate transport and signal transduction [5]. Indeed recent observations by our group suggest that genetic variability of $\mathrm{Rh}$ proteins may influence glucose transport in the erythrocyte [6].

Maternal-fetal genetic differences within the normal variability in membrane transport and signal transduction could contribute significantly to the normal variability of intrauterine developmental parameters [2]. Moreover, effects of maternal-fetal competition connected with differences in relative efficiency of substrate transport and/or signal transduction could be amplified by environmental conditions including seasonal variation $[7,8]$.

In the present note we have searched for possible effects of joint mother-newborn Rh phenotype on intrauterine growth in two samples of consecutive infants from healthy puerperae.

\section{Subjects and methods}

A consecutive sample of 5291 infants including all newborns delivered in the period January 1993December 1996 in the Maternity Department of the University of Sassari and a consecutive sample of 984 infants including all newborns delivered during 1996 in the Maternity Department of the University of Rome Tor Vergata have been studied along with their mothers. 
Table 1

Birth weight, season of birth and maternal $\mathrm{Rh}$ phenotype. Values marked with asterisk refer to analysis on logo of birth weight

\begin{tabular}{|c|c|c|c|c|c|c|c|c|c|c|c|c|}
\hline & \multicolumn{6}{|c|}{ Males } & \multicolumn{6}{|c|}{ Females } \\
\hline & \multicolumn{3}{|c|}{ Mother $\mathrm{Rh}(-)$} & \multicolumn{3}{|c|}{ Mother $\mathrm{Rh}(+)$} & \multicolumn{3}{|c|}{ Mother $\mathrm{Rh}(-)$} & \multicolumn{3}{|c|}{ Mother $\mathrm{Rh}(+)$} \\
\hline & mean $(\mathrm{g})$ & S.E. & $n^{\circ}$ & mean $(\mathrm{g})$ & S.E. & $\mathrm{n}^{\circ}$ & mean $(\mathrm{g})$ & S.E. & $\mathrm{n}^{\circ}$ & $\operatorname{mean}(\mathrm{g})$ & S.E. & $\mathrm{n}^{\circ}$ \\
\hline \multicolumn{13}{|l|}{ Sassari } \\
\hline winter & 3203 & 74 & 39 & 3310 & 21 & 622 & 3212 & 58 & 46 & 3173 & 19 & 616 \\
\hline spring & 3352 & 93 & 32 & 3304 & 21 & 633 & 3201 & 97 & 35 & 3170 & 20 & 559 \\
\hline summer & 3319 & 65 & 35 & 3285 & 19 & 677 & 3274 & 56 & 45 & 3181 & 20 & 624 \\
\hline autumn & 3449 & 86 & 32 & 3304 & 20 & 652 & 3331 & 67 & 36 & 3139 & 19 & 608 \\
\hline \multicolumn{13}{|l|}{ Rome } \\
\hline winter & 2868 & 219 & 12 & 3249 & 63 & 93 & 3155 & 93 & 10 & 3218 & 53 & 103 \\
\hline spring & 3252 & 108 & 17 & 3310 & 49 & 120 & 3026 & 178 & 14 & 3162 & 46 & 103 \\
\hline summer & 3164 & 119 & 14 & 3296 & 48 & 135 & 3102 & 130 & 15 & 3126 & 45 & 99 \\
\hline autumn & 3456 & 131 & 14 & 3307 & 42 & 122 & 3254 & 155 & 14 & 3228 & 46 & 99 \\
\hline \multicolumn{13}{|c|}{ Variance analysis } \\
\hline Main effect & \multicolumn{3}{|c|}{$0.0070 .006^{*}$} & \multicolumn{3}{|c|}{ N.S. } & \multicolumn{3}{|c|}{ N.S. } & \multicolumn{3}{|c|}{ N.S. } \\
\hline Season & \multicolumn{3}{|c|}{$0.0090 .009 *$} & \multicolumn{3}{|c|}{ N.S. } & \multicolumn{3}{|c|}{ N.S. } & \multicolumn{3}{|c|}{ N.S. } \\
\hline Population & \multicolumn{3}{|c|}{ N.S. } & \multicolumn{3}{|c|}{ N.S. } & \multicolumn{3}{|c|}{ N.S. } & \multicolumn{3}{|c|}{ N.S. } \\
\hline Interaction & \multicolumn{3}{|c|}{ N.S. } & \multicolumn{3}{|c|}{ N.S. } & \multicolumn{3}{|c|}{ N.S. } & \multicolumn{3}{|c|}{ N.S. } \\
\hline
\end{tabular}

$\mathrm{Rh}(\mathrm{D})$ blood group was determined according to standard laboratory method. Variance analysis was performed by SPSS programs [12]. The procedure was carried out on both $\log _{10}$ of birth weight and on raw data.

Among $\mathrm{Rh}(-)$ mothers a direct Coombs test was present in 6 newborns in Sassari (Sardinia) and in 2 newborns in Rome. Excluding these subjects from analyses, the results in Table 1 and in Table 2 remain practically unchanged.

In few infants $\mathrm{Rh}$ determination has not been performed: this explains the fact that the number of male newborns from $\mathrm{Rh}(-)$ mothers is greater in Table 1 than in Table 2.

\section{Results}

Table 1 shows the weight of newborns in relation to season of birth and to Rh phenotype of the mother. In male infants from $\mathrm{Rh}(-)$ mothers there is a significant association between birth weight and season of birth. The association is significant after Bonferroni correction for multiple comparison. Variance analysis evaluates the effects of the two independent variables: season of birth (four categories) and population (two categories: Sassary and Rome) on birth weight (dependent variable). Overall (main effect) there is a significant effect on birth weight in males from $\mathrm{Rh}(-)$ mothers. This effect is due to season while the variable population has no significant effect and there is no significant interaction between the two independent variables, sea- son and population. In brief, the analysis shows that the effect of season on birth weight in male newborns from $\mathrm{Rh}(-)$ mothers is the same in Rome and Sassari.

Tukey test has shown that birth weight is significantly lower in infants born in winter than in infants born in autumn. Such difference is $246 \mathrm{~g}$ in Sassari and $588 \mathrm{~g}$ in Rome. The mean value of difference (weighted for the different number of newborns in the two samples) is $327 \mathrm{~g}$ ( $p<0.003$; after correction for multiple comparison $p<0.02)$.

The strength of association among birth weight, $\mathrm{Rh}$ and season of birth seems slightly variable in different years. In the population of Sassari a higher birth weight in male infants born in autumn from $\mathrm{Rh}(-)$ mother has been observed in 1993, 1994 and 1995 but not in 1996 (data not shown).

An analysis of gestational duration in relation to season of birth and Rh phenotype of the mother has shown no significant association.

An analysis of variance and covariance has also been performed considering as dependent birth weight and as independent season of birth, population and gestational duration (covariate). Controlling for the effect of gestational duration, the association between birth weight and season of birth remains significant.

Table 2 shows the weight of male newborns in relation to season of birth and Rh phenotype. The association between birth weight and season is significant in $\mathrm{Rh}(+)$ male newborns from $\mathrm{Rh}(-)$ mothers only.

$\mathrm{Rh}(\mathrm{D})$ distribution in mothers and infants (all infants and males and females separately) has not shown significant association with season of birth. Possible 
Table 2

Birth weight in relation to season of birth and Rh phenotype in male newborns. Values marked with asterisk refer to analysis on $\log _{10}$ of birth weight

\begin{tabular}{|c|c|c|c|c|c|c|c|c|c|c|c|c|}
\hline \multirow[t]{2}{*}{$\begin{array}{l}\text { mother } \\
\text { infant }\end{array}$} & \multicolumn{3}{|c|}{$\begin{array}{l}\mathrm{Rh}(-) \\
\operatorname{Rh}(-)\end{array}$} & \multicolumn{3}{|c|}{$\begin{array}{l}\mathrm{Rh}(-) \\
\operatorname{Rh}(+)\end{array}$} & \multicolumn{3}{|c|}{$\begin{array}{l}\operatorname{Rh}(+) \\
\operatorname{Rh}(-)\end{array}$} & \multicolumn{3}{|c|}{$\begin{array}{l}\mathrm{Rh}(+) \\
\mathrm{Rh}(+)\end{array}$} \\
\hline & mean $(\mathrm{g})$ & S.E. & $\mathrm{n}^{\circ}$ & $\operatorname{mean}(\mathrm{g})$ & S.E. & $n^{\circ}$ & mean $(\mathrm{g})$ & S.E. & $\mathrm{n}^{\circ}$ & mean $(\mathrm{g})$ & S.E. & $\mathrm{n}^{\circ}$ \\
\hline \multicolumn{13}{|l|}{ Sassari } \\
\hline winter & 3303 & 200 & 6 & 3200 & 82 & 30 & 3248 & 111 & 27 & 3313 & 20 & 578 \\
\hline spring & 3422 & 87 & 12 & 3343 & 144 & 19 & 3314 & 108 & 28 & 3312 & 21 & 590 \\
\hline summer & 3223 & 326 & 3 & 3315 & 67 & 31 & 3318 & 76 & 32 & 3287 & 20 & 634 \\
\hline autumn & 3204 & 153 & 9 & 3545 & 98 & 23 & 3365 & 147 & 29 & 3303 & 20 & 604 \\
\hline \multicolumn{13}{|l|}{ Rome } \\
\hline winter & 3165 & 325 & 2 & 3075 & 221 & 8 & 3433 & 179 & 3 & 3292 & 58 & 83 \\
\hline spring & 3320 & 208 & 6 & 3214 & 129 & 11 & 2974 & 157 & 10 & 3389 & 41 & 107 \\
\hline summer & 3252 & 252 & 5 & 3114 & 131 & 9 & 3228 & 139 & 13 & 3323 & 51 & 119 \\
\hline autumn & 3486 & 177 & 5 & 3439 & 186 & 9 & 3201 & 134 & 16 & 3326 & 44 & 105 \\
\hline \multicolumn{13}{|c|}{ Variance analysis (effects of season of birth and locality (population) on birth weight) } \\
\hline Main effect & & S. & & 0.02 & $0.045 *$ & & & S. & & & N.S. & \\
\hline Season & & S. & & 0.02 & $0.043 *$ & & & S. & & & J.S. & \\
\hline Population & & S. & & & I.S. & & & $S$. & & & J.S. & \\
\hline Interaction & & S. & & & I.S. & & & S. & & & J.S. & \\
\hline
\end{tabular}

distortion of the joint mother-infant Rh distribution in relation to season of birth has been examined without significant results.

\section{Discussion}

Because of the clinical relevance of hemolytic disease of the newborn due to maternal-fetal incompatibility in $\mathrm{Rh}$ blood groups, studies on this system have been focused on immunological aspects. These studies eventually relieved the clinical burden but shadowed the biological problem of maintenance of a polymorphism showing a strong heterozygote disantvantage. It is likely that the hemolytic disease of the newborn is an accidental phenomenon largely compensated by a still unknown advantage connected with some important function of Rh system in the maternal-fetal relationship.

Recently, it has been shown that $\mathrm{Rh}$ is a transport protein. In addition, we have recently shown that in NIDDM the mean level of glycosilated $\mathrm{Hb}$ (HbA1c) is higher in $\mathrm{Rh}(+)$ than in $\mathrm{Rh}(-)$ suggesting that glucose transport in red blood cells may be related to $\mathrm{Rh}$ protein [6]. This prompted us to search for a possible relationship between $\mathrm{Rh}$ system and intrauterine development in a perspective of maternal-fetal difference in transport-function.

As pointed by Sing et al. [11], the first step in the analysis of genetic architecture of multifactorial variables including developmental parameters and common diseases is the estimate of the joint distribution of genetic and environmental causal agents. Moreover, when studying the effect of genetic and environmental factor on intrauterine development an obvious subdivision is that between males and females [11]. In fact is well known that these two classes show differences in the pattern of intrauterine development, endocrine functions and metabolism.

The present data from two unrelated populations show that in newborns from $\mathrm{Rh}(-)$ mothers the birth weight is higher in those conceived in the winter (born in autumn) than in those conceived in other seasons. The phenomenon is very clear in $\mathrm{Rh}(+)$ newborns conceived by $\mathrm{Rh}(-)$ mothers, suggesting an involvement of $\mathrm{Rh}$ system in the maternal-fetal metabolic relationship with selective effects opposite to that of Rh hemolytic disease.

Assuming that maternal-fetal genetic differences within the normal variability of receptors, membrane transport and signal tranduction could contribute significantly to the normal variability of intrauterine development [2,4], we propose a metabolic interpretation centered on maternal-fetal differences in transport rate depending on the joint Rh phenotype. If the density of $\mathrm{D}$ protein is greater in the infant than in the mother, the balance would be in favour of the infant who may take advantage for its development when he is conceived in the cold season (and born in autumn). Such effects are much more evident in males than in females.

At present, however, the possibility that the association is causally due to some gene near $\mathrm{Rh}$ and in linkage disequilibrium with it cannot be excluded. In fact, a number of genes with important metabolic functions 
are clustered on the short arm of chromosome 1. Starting from telomere there are the following loci: Glucose Dehydrogenase, 6-Phosphogluconate Dehydrogenase, (Rh cluster), UDP Galactose-6-Epimerase, Glucose Transporter Protein 1, Glucose Transporter Protein 5, Phosphoglucomutase-1, Amylase loci (AMY1A - salivary; AMY1B - salivary; AMY2A - pancreatic; AMY2B - pancreatic) [10].

\section{References}

[1] P. Agree and J.P. Cartron, Molecular biology of the Rh antigens, Blood 78 (1991), 551-563.

[2] E. Bottini, E. Cosmi, M. Nicotra, G. Santeusanio, M. La Torre, N. Bottini and N. Lucarini, The genetics of signal transduction and feto-maternal relationship. A study of cytosolic low molecular weight phosphotyrosine phosphatase, Disease Markers 14 (1998), 143-150.

[3] J.P. Cartron, Vers une approache moleculaire de la structure du polymorphism et de la function des groups sanguins, Transf. Clin. Biol. 3 (1996), 181-210.

[4] J.C. Cross, Z. Werb and S.J. Fisher, Implantation and the placenta: key pieces of the development puzzle, Science $\mathbf{2 6 6}$ (1994), 1508-1518.

[5] M.A. Devynck, Do cell membrane dynamics participate in resistance? Lancet 11 (1995), 336-337.

[6] F. Gloria-Bottini, E. Antonacci, N. Bottini, A. Ogana, P. Borgiani, G. De Santis and N. Lucarini, Rh blood groups and diabetic disorders. Is there an effect on glycosilated hemoglobin level? Human Biology 72 (2000), 287-294.

[7] F. Gloria-Bottini, N. Lucarini and M. La Torre, Birth dates, Nature 379 (1996), 395.

[8] F. Gloria-Bottini, N. Lucarini, R. Palmarino, M. La Torre, A. Amante and E. Bottini, ACP1 and human adaptability. 2. Association with season of conception, Hum. Genet. 101 (1997), 158-164.

[9] C.H. Huang, The human Rh50 glycoprotein gene. Structural organization and associated splicing defect resulting in Rh(null) disease, J. Biol. Chem. 273 (1998), 2207-2213.

[10] V.A. McKusik, Mendelian inheritance in man, (11th ed.), The Johns Hopkins University Press, Baltimore, 1994.

[11] C.F. Sing, M.B. Havilland and S.L. Reilly, Genetic architecture of common multifactorial diseases, The Variation In The Human Genome, John Wiley \& Sons, Ciba Foundation Symposium, 1996, 1997, 211-232.

[12] SPSS/PC+ Versione 5.0, Chicago SPSS Inc., 1992.

[13] M.J. Telen, Erythrocyte blood group antigens: not so simple after all, Blood 85 (1995), 299-306. 


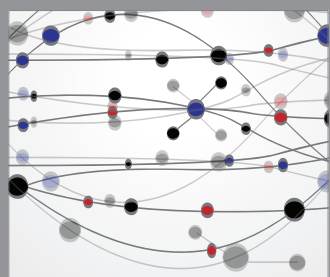

The Scientific World Journal
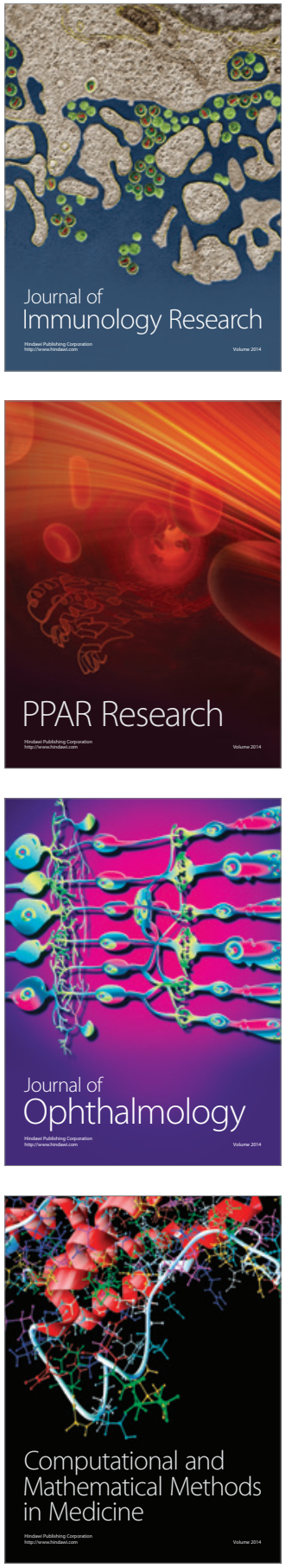

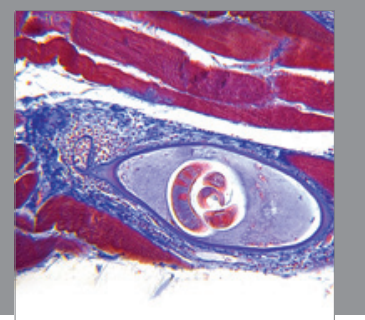

Gastroenterology

Research and Practice
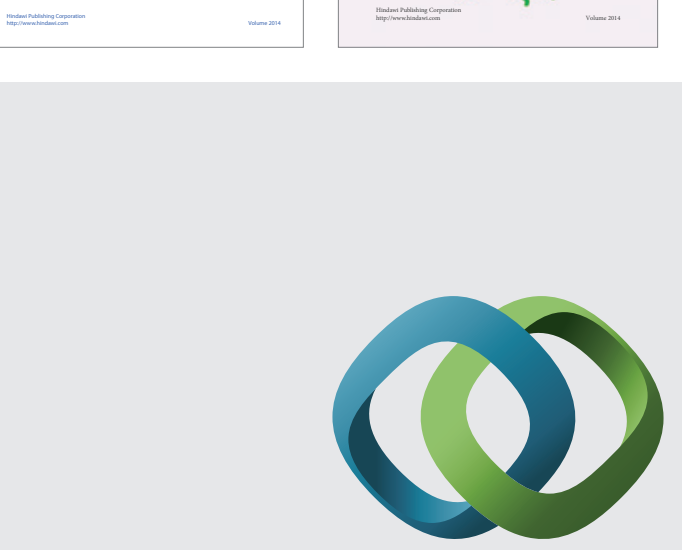

\section{Hindawi}

Submit your manuscripts at

http://www.hindawi.com
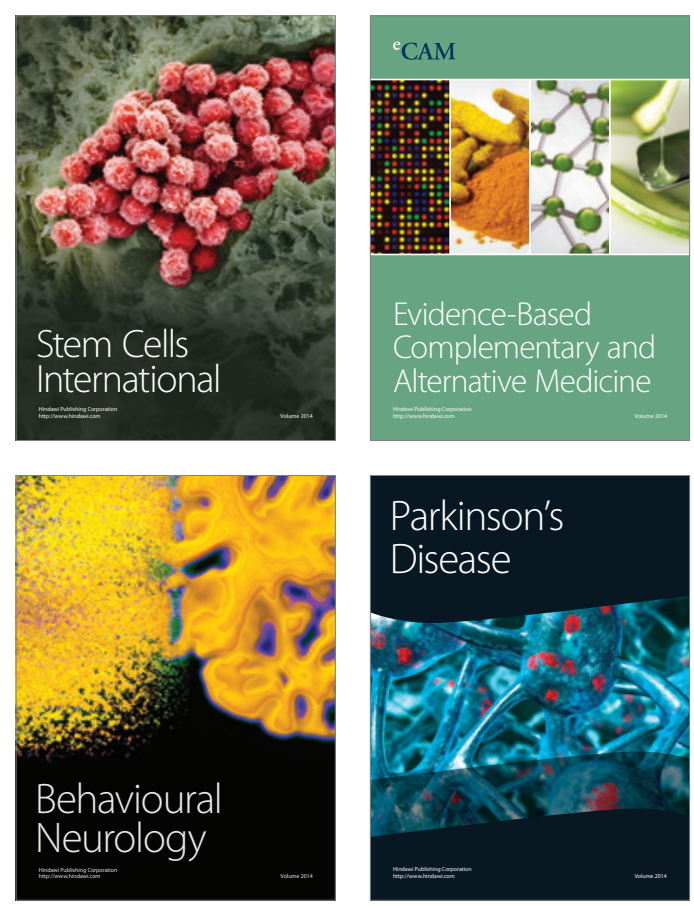

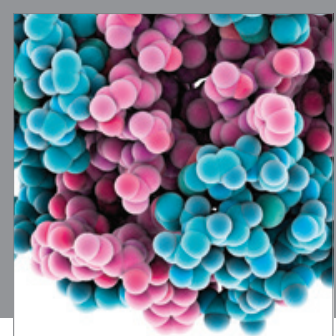

Journal of
Diabetes Research

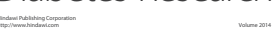

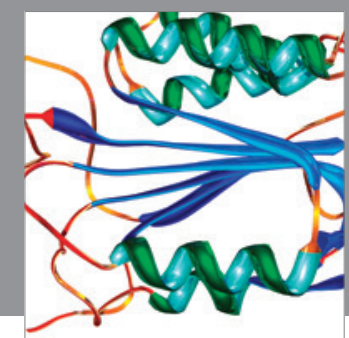

Disease Markers
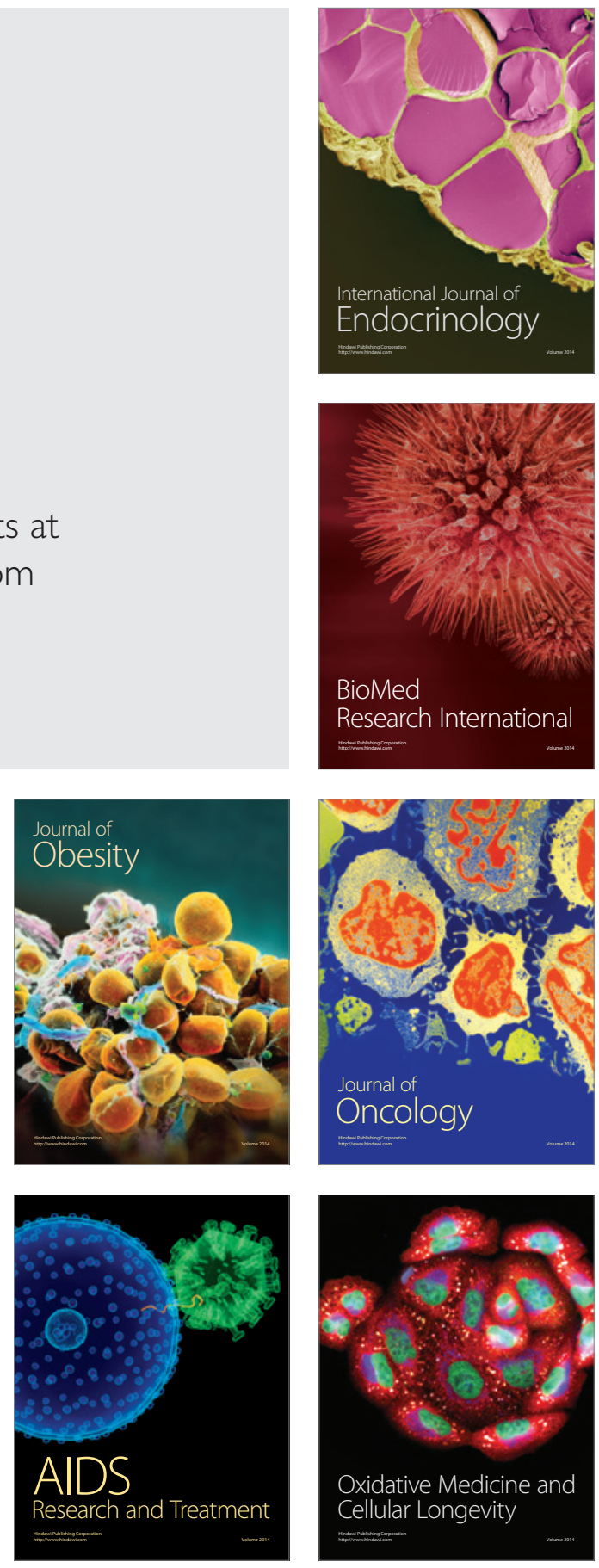